\title{
ASPEK TEKNIS DAN PEMANFAATAN KAPAL INKA MINA DI PPP TEGALSARI, TEGAL DAN PPS CILACAP, JAWA TENGAH
}

\author{
Utilization Of The Inka Mina In PPP and PPS Tegalsari Cilacap, Central Java
}

\author{
Oleh \\ Deni A. Soeboer ${ }^{1 *}$, Budhi H. Iskandar ${ }^{2}$, Mohammad Imron ${ }^{2}$, Wienda J. Ardiyani ${ }^{3}$ \\ ${ }^{1}$ Staf Pengajar Pascasarjana TPL-Dep PSP-FPIK-IPB \\ ${ }^{2}$ Staf Pengajar Departemen PSP-FPIK-IPB \\ ${ }^{3}$ Mahasiswa Program Studi Teknologi dan Manajemen Perikanan Tangkap \\ *Korespondensi: denisoeboer@gmail.com
}

\begin{abstract}
ABSTRAK
Pemerintah melalui Instruksi Presiden No. 01 tahun 2010 tentang Percepatan Pelaksanaan Prioritas Nasional tahun 2010 dan Peraturan Presiden No. 10 tahun 2011 membantu nelayan dalam pelaksanaan percepatan pembangunan di tahun 2010. Salah satu program yang dilakukan yaitu dengan memberikan bantuan 1000 kapal bagi nelayan. Hingga tahun 2013 sudah dibangun 208 kapal Inka Mina yang tersebar di seluruh daerah di Indonesia. Penelitian ini bertujuan untuk mengetahui sistem kerja bagi kelompok nelayan dalam mengoperasikan kapal bantuan dan mengetahui pemanfaatan kapal bantuan pemerintah bagi nelayan di Pelabuhan Perikanan Pantai Tegalsari Kota Tegal dan Pelabuhan Perikanan Samudera Cilacap Kota Madya Cilacap, Jawa Tengah. Metode penelitian yang digunakan adalah metode deskriptif dengan melakukan survei di Tegal dan Cilacap. Hasil penelitian menunjukkan bahwa Kapal Inka Mina yang diberikan kepada nelayan di PPP Tegalsari dan PPS Cilacap sudah dapat dimanfaatkan oleh nelayan dengan perubahan terhadap beberapa bagian kapal seperti melaminasi ulang dek kapal, meninggikan sheer, memperbaiki tutup dan bagian dinding palka, mengatur ulang sistem pendingin, menghilangkan bagian atas dek kapal yang dianggap kurang berfungsi, membuat ruang alat tangkap, menambahkan bilge keel, memperbaiki instalasi lampu sebagai alat bantu penangkapan. Perubahan alat tangkap dilakukan oleh nelayan di Cilacap, alat tangkap yang semula adalah longline diubah menjadi gillnet.
\end{abstract}

Kata kunci : Cilacap, Inka Mina, Kapal, Tegal

\begin{abstract}
The government through the Presidential Instruction No. 01/2010 about the acceleration of the implementation of national priorities president of the regulation in 2010 and Presidential Regulation No. 10/2011 help fishermen in the implementation of the acceleration of development in 2010. One of the programs is giving 1000 fishing vessel for fisherman. Until 2013 was built 208 Inka Mina fishing vessel all of Indonesia. The objectives of this research are how to know the working system of fishermen in operating, and utilization of the fishing vessel in PPP Tegalsari, and PPS Cilacap of Central Java. Research method used is descriptive method to do a survey in Cilacap and Tegal. The research results show that a ship in PPP Tegalsari and PPS Cilacap can be used by fishermen with changes to several section of a vessel as like repeated laminates deck of a ship, exalt sheer, fix the cover and the piece of wall of fish hold, reinstalled a cooling system, make room of fishing gear, added bilge keel, fix the lights as installation the tools arrest. Change fishing gear carried by fisherman in cilacap, which was initially is longline converted into gillnet.
\end{abstract}

Keywords : Cilacap, Inka Mina, Ships, Tegal 


\section{PENDAHULUAN}

Instruksi Presiden No. 01 tahun 2010 [INPRES] 2010 tentang Percepatan Pelaksanaan Prioritas Pembangunan Nasional Tahun 2010 merupakan awal mula perencanaan pemberian kapal bantuan bagi nelayan untuk membantu percepatan pelaksanaan pembangunan di tahun 2010 saat itu, selanjutnya melalui Peraturan Presiden No. 10 tahun 2011 [PERPRES] 2011 lebih ditekankan lagi mengenai program bantuan tersebut. Presiden secara langsung meminta kepada menteri-menteri terkait untuk membantu percepatan kesejahteraan nelayan sehingga program Peningkatan Kesejahteraan Nelayan (PKN) dapat terealisasikan. Program yang dilakukan oleh 11 Kementrian ini bertujuan untuk membantu kesejahteraan nelayan baik dalam aspek sosial, ekonomi, pengadaan fasilitas maupun kegiatan usaha untuk meningkatkan taraf hidupnya. Program Peningkatan Kehidupan Nelayan (PKN) merupakan program dari Kementerian Kelautan Perikanan (KKP) yang dicanangkan untuk nelayan. Salah satu bentuk dari program ini adalah pemberian bantuan kapal bagi nelayan. Bantuan kapal yang diberikan beraneka ragam, mulai dari ukuran kapal 10 GT hingga 30 GT.

Pemberian kapal ini umumnya belum mempertimbangkan berbagai aspek kedaerahan dari nelayan maupun daerah penangkapan ikan (fishing ground). Berbagai kendala tersebut akhirnya membuat nelayan cenderung menggunakan kapal milik mereka sendiri dan menyia-nyiakan kapal bantuan pemerintah yang telah diberikan ini. Kapal bantuan yang tidak digunakan biasanya hanya dibiarkan saja tanpa perawatan bahkan ada pula yang dijual untuk memenuhi kebutuhan sehari-hari. Ukuran kapal yang terlalu besar terkadang tidak sesuai dengan kondisi perairan daerah penangkapan yang dangkal, sehingga menjadikan kapal bantuan tersebut menjadi sia-sia. Berita mengenai ketidaksuksesan nelayan dalam mengoperasikan kapal bantuan khususnya Kapal Inka Mina (> 30 GT) merupakan sebagian kecil kisah nelayan dalam pelaksanaan program PKN. Kesuksesan yang dialami nelayan dalam mengoperasikan Kapal Inka Mina pun tidak sedikit. Berbagai cara dilakukan oleh nelayan agar tetap dapat melaksanakan operasi penangkapan dengan Kapal Inka Mina, mulai dari saling bertukar pikiran, belajar ke nelayan lain, mengganti alat tangkap hingga mendapat bantuan pemerintah sebagai modal dalam pengoperasian kapal.

Ketidaksesuaian penggunaan kapal bantuan pemerintah dan berbagai cara yang dilakukan untuk kesuksesan pengoperasian Kapal Inka Mina yang menjadi topik utama dalam penelitan ini. Sejauh mana nelayan dapat menggunakan kapal bantuan pemerintah sebagaimana mestinya, dan sejauh mana pula pemerintah dapat melihat kondisi nelayan yang menerima bantuan kapal tersebut sehingga dapat dilihat ketidaksesuaian penggunaan kapal bantuan pemerintah dan solusi yang dapat diterapkan bagi nelayan yang gagal mengoperasikan Kapal Inka Mina dengan melihat sistem yang digunakan oleh nelayan di Pelabuhan Perikanan Pantai (PPP) Tegalsari dan Pelabuhan Perikanan Samudera (PPS) Cilacap sehingga dapat meraih kesuksesan dalam mengoperasikan kapal tersebut. Adapun tujuan dari penelitian ini untuk mengetahui aspek teknis kapal bantuan Inka Mina di Pelabuhan Perikanan Pantai Tegalsari Kota Tegal dan Pelabuhan Perikanan Samudera Cilacap Kota Madya Cilacap, Jawa Tengah, mengetahui pemanfaatan kapal bantuan pemerintah bagi nelayan di Pelabuhan Perikanan Pantai Tegalsari Kota Tegal dan Pelabuhan Perikanan Samudera Cilacap Kota Madya Cilacap, Jawa Tengah.

\section{METODOLOGI PENELITIAN}

Penelitian ini dilakukan pada bulan Maret hingga September 2014. di Pelabuhan Perikanan Pantai Tegalsari Kota Tegal dan Pelabuhan Perikanan Samudera Cilacap Kota Madya Cilacap, Jawa Tengah. Alat yang digunakan dalam penelitian berupa alat tulis, laptop, kamera, dan kuisioner. Beberapa aplikasi terkait juga digunakan dalam penelitian ini untuk keperluan pengolahan data. Penelitian dilakukan terhadap Kapal Inka Mina > 30 GT dan komunitas nelayan yang mengoperasikan kapal tersebut [DJPT-KKP.A] 2014. Penelitian ini dilakukan dengan menggunakan metode deskriptif. Nazir M (1988) Metode pengambilan data berupa observasi langsung ke pelabuhan-pelabuhan yang dijadikan lokasi penelitian dan wawancara kepada beberapa nelayan yang dijadikan sumber data. 
Penentuan responden langsung kepada nelayan yang memperoleh kapal Inka Mina di Tegal dan Cilacap. Total responden di Tegal dan Cilacap adalah 6 kelompok nelayan.

Data dalam penelitian ini terdiri dari data primer dan data sekunder. Data primer diperoleh dari hasil observasi dan wawancara langsung dengan nelayan penerima kapal bantuan berupa data kegiatan pengoperasian kapal bantuan, data spesifikasi kapal dan alat tangkap. Data sekunder diperoleh dari instansi terkait yang berhubungan dengan program kapal bantuan ini berupa data penerima dan proses penerimaan kapal bantuan dari pemerintah pusat kepada nelayan penerima.

Pengolahan data dilakukan dengan cara tabulasi atau pengelompokan data berdasarkan hasil wawancara. Pengolahan data dengan cara demikian dilakukan agar mempermudah analisis data selanjutnya. Pengolahan data dilakukan terhadap beberapa parameter seperti perhitungan daya tenaga penggerak dan kecepatan kapal dan rasio dimensi utama kapal.

\section{Daya tenaga penggerak dan kecepatan kapal}

Perhitungan EHP (Effective horse power) dilakukan untuk menghitung daya efektiv yang dihasilkan kapal yaitu dengan menggunakan rumus yang dijelaskan oleh Nomura dan Yamazaki (1977).

$$
\mathrm{EHP}=\mathrm{BHP} \times 0,94 \times 0,23 \text {. }
$$

dimana; BHP = Brake horse power

Selanjutnya dilakukan perhitungan IHP (Indicated horse power) berdasarkan kecepatan kapal dan ton displacement kapal dengan formula Nomura dan Yamazaki (1977).

$$
\mathrm{IHP}=\frac{\Delta^{2 / 3} x V^{3}}{C} .
$$

$\Delta=$ ton displacement (ton)

$\mathrm{V}=$ kecepatan kapal (knot)

$\mathrm{C}=$ admiralty coefficient

Perhitungan EHP berdasarkan nilai IHP yang telah diperoleh dilakukan menggunakan formula Nomura dan Yamazaki (1977). Kecepatan efektif kapal dihitung dengan menggunakan rumus dari Nomura dan Yamazaki (1977).

$$
\mathrm{V}=\sqrt[3]{\frac{I H P X C}{\Delta^{2 / 3}}}
$$

\section{Rasio dimensi utama kapal}

Perhitungan rasio dimensi utama kapal dilakukan berdasarkan nilai panjang (L), lebar (B), dan dalam (D). Menurut Mulyanto (2012) ukuran utama panjang kapal (L) mempunyai pengaruh pada kecepatan kapal dan pada kekuatan memanjang kapal. Rasio dimensi utama Kapal Inka Mina di Cilacap dan Tegal akan dibandingkan dengan nilai rasio dimensi utama kapal ikan berdasarkan jenis alat tangkap pada penelitian Iskandar dan Pudjiati (1995).

Tabel 1 Kisaran rasio dimensi utama jenis kapal ikan di Indonesia

\begin{tabular}{clrrc}
\hline No. & Metode Operasi & L/B & L/D & B/D \\
\hline 1 & Static gear & $2,83-11,12$ & $4,58-17,28$ & $0,96-4,68$ \\
2 & Encircling gear & $2,60-9,30$ & $4,55-17,43$ & $0,56-5,00$ \\
3 & Towed/dragged gear & $2,86-8,30$ & $7,20-15,12$ & $1,25-4,41$ \\
4 & Multipurpose gear & $2,88-9,42$ & $8,69-17,15$ & $0,53-6,09$ \\
\hline
\end{tabular}

Analisis data deskripsi dilakukan dengan membandingkan tujuan program bantuan kapal tersebut dengan kondisi penerima bantuan. Analisis ini dimaksudkan untuk mengetahui tujuan dari pelaksanaan program bantuan kapal ini sudah tercapai atau belum disesuaikan dengan kondisi dan kemampuan penerima. Sehingga akan terlihat bahwa bantuan ini dapat bermanfaat dalam 
meningkatkan kesejahteraan nelayan. Selain itu, analisis data juga dilakukan untuk melihat sejauh mana program bantuan kapal ini dapat dilakukan oleh nelayan yang mendapat bantuan, sehingga dapat menjadi acuan bagi nelayan lainnya yang juga menerima bantuan tersebut.

\section{HASIL DAN PEMBAHASAN}

\section{Spesifikasi Kapal Inka Mina}

Kapal Inka Mina di Tegal dan Cilacap memiliki ukuran dimensi yang berbeda baik dari ukuran panjang, lebar, dan dalam. Ukuran kapal di Tegal lebih kecil dibandingkan dengan ukuran kapal di Cilacap [DJPT-KKP.B] 2014. Rasio dimensi kapal digunakan untuk menghitung perbandingan panjang, lebar, dan dalam Kapal Inka Mina, dari hasil perhitungan diperoleh seperti pada Tabel 2 dan Tabel 3. Kapal Inka Mina baik di Tegal dan Cilacap masih tergolong dalam kategori Kapal Perikanan yang sesuai menurut Pudjiati, 1995.

Tabel 2 Dimensi utama dan rasio dimensi utama Kapal Inka Mina di Cilacap

\begin{tabular}{lrrrccc}
\hline \multicolumn{1}{c}{ Lokasi } & L & B & D & L/B & L/D & B/D \\
\hline Cilacap & 18,05 & 4,8 & 1,7 & 3,76 & 10,62 & 2,82 \\
$\begin{array}{l}\text { Kisaran rasio dimensi kapal } \\
\text { di Indonesia (static gear) }\end{array}$ & & & & $2,83-11,12$ & $4,58-17,28$ & $0,96-4,68$ \\
\hline
\end{tabular}

Alat tangkap yang digunakan dalam pengoperasian Kapal Inka Mina di Cilacap adalah gillnet yang tergolong dalam kategori static gear. Oleh karena itu nilai kisaran dimensi rasio yang digunakan merupakan kisaran untuk kapal yang menggunakan alat tangkap static gear. Kapal Inka Mina di Cilacap berada dalam nilai kisaran ukuran kapal static gear untuk kisaran berdasarkan Iskandar dan Pudjiati (1995).

Tabel 3 Dimensi utama dan rasio dimensi utama Kapal Inka Mina di Tegal

\begin{tabular}{lrccccc}
\hline \multicolumn{1}{c}{ Lokasi } & L & B & D & L/B & L/D & B/D \\
\hline \multirow{2}{*}{ Tegal } & 16,67 & 5,05 & 2,18 & 3,30 & 7,65 & 2,32 \\
& 17,89 & 5,30 & 2,05 & 3,38 & 8,73 & 2,59 \\
Kisaran rasio dimensi kapal di & & & & $2,60-9,30$ & $4,55-17,43$ & $0,56-5,00$ \\
Indonesia (encircling gear) $^{*}$ & & & & & & \\
\hline
\end{tabular}

Kapal Inka Mina di Tegal menggunakan purse seine yang tergolong dalam kategori encircling gear, dengan membandingkan kisaran rasio dimensi kapal milik Iskandar dan Pudjiati (1995) maka terlihat bahwa Kapal Inka Mina di Tegal memiliki rasio dimensi utama yang berada dalam kisaran yang ada. Kapal purse seine umumnya membutuhkan kemampuan lingkar yang besar sehingga memiliki ukuran panjang kapal yang tidak terlalu besar (Mulyanto, 2012).

Perbandingan L/B akan berpengaruh terhadap kecepatan yang dimiliki oleh kapal tersebut, semakin tinggi nilai perbandingan panjang dan lebar suatu kapal maka kecepatan yang dimiliki juga akan semakin besar. Perbandingan L/D akan berpengaruh terhadap kekuatan memanjang kapal, semakin besar perbandingan L/D yang dimiliki maka kekuatan memanjang yang dimiliki kapal akan semakin besar. Perbandingan B/D akan menunjukkan kekuatan melebar suatu kapal. 


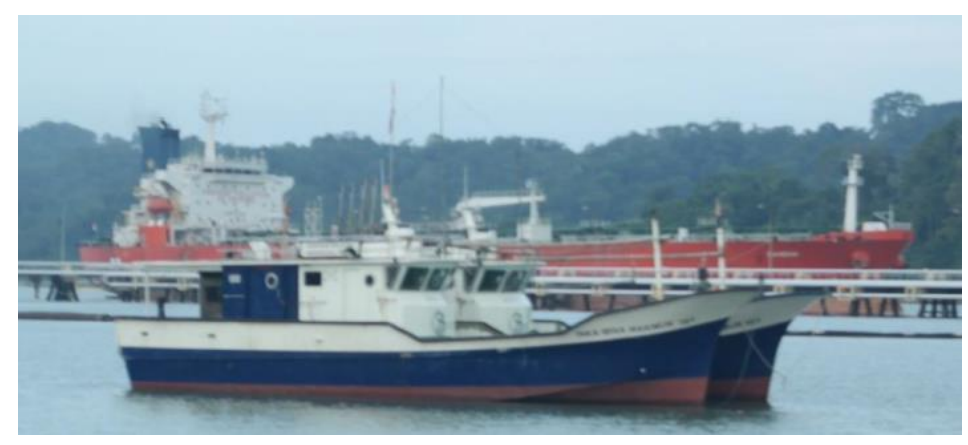

Gambar 1 Kapal INKA MINA Cilacap

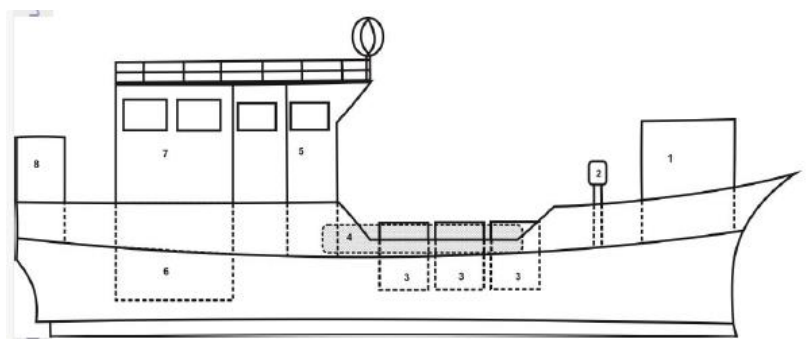

(a)

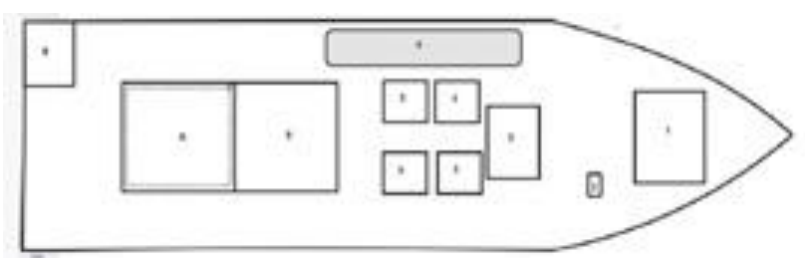

(b)

Keterangan:

1. Rumah alat tangkap

2. Line hauller
3. Palka ikan

4. Alat tangkap
5. Rumah kemudi

6. Ruang mesin 8 . Toilet

Gambar 2 General Arrangement Kapal Inka Mina di Cilacap (a) tampak samping (b) tampak atas

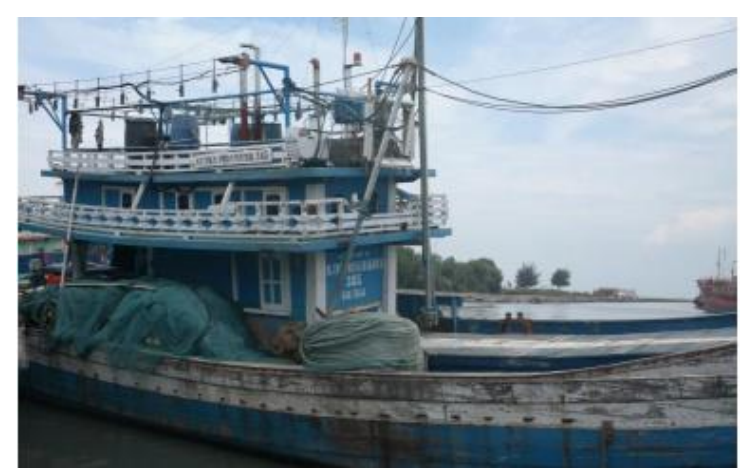

Gambar 3 Kapal Inka Mina di Tegal 


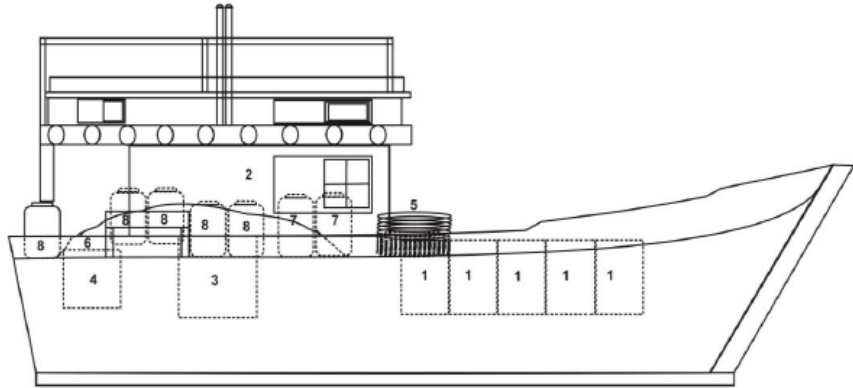

(a)

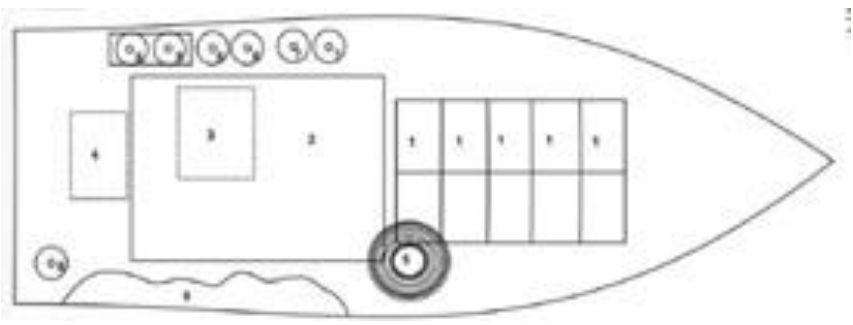

(b)

Skala : tanpa skala
\begin{tabular}{|l|l|l|}
\hline Dimensi & $\mathrm{a}(\mathrm{m})$ & $\mathrm{b}(\mathrm{m})$ \\
\hline LOA & 16,67 & 17,89 \\
\hline $\mathrm{B}$ & 5,05 & 5,30 \\
\hline $\mathrm{D}$ & 2,18 & 2,05 \\
\hline
\end{tabular}

Keterangan:

1. Palka ikan

3. Ruang mesin

5. Purse line

7. Tanki bahan bakar

2. Ruang $\mathrm{ABK}$

4. Ruang alat tangkap

6. Alat tangkap

8. Tanki air bersih

Gambar 4 General Arragement Kapal Inka Mina di Tegal (a) tampak samping (b) tampak atas

\section{Hubungan Daya Tenaga Penggerak dengan Kecepatan Kapal}

Pengoperasian Kapal Inka Mina di Cilacap umumnya dilakukan dengan kecepatan 4-5 knot oleh nelayan. Berdasarkan perhitugan yang dilakukan dengan nilai daya $140 \mathrm{HP}$ dan nilai ton displacement sebesar 83,95 maka kecepatan efektif yang dapat dicapai oleh kapal di Cilacap ini adalah sebesar 9 knot dengan nilai EHP sebesar 30,26 HP. Apabila nelayan di Cilacap terbiasa menggunakan Kapal Inka Mina dengan kecepatan 4-5 knot itu berarti nelayan di Cilacap hanya menggunakan setengah dari kemampuan maksimum kecepatan kapal yang sebenarnya. Effective horsepower (EHP) merupakan daya yang dibutuhkan agar kapal dapat bergerak secara substansial (Nomura dan Yamazaki, 1977).

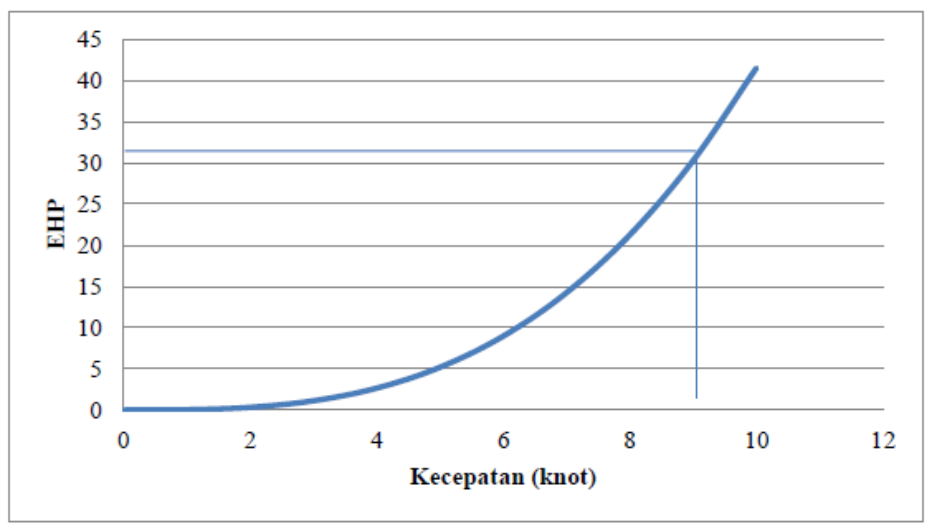

Gambar 5 Kurva kecepatan maksimum Kapal Inka Mina di Cilacap

Nelayan di Tegal umumnya mengoperasikan kapal dengan kecepatan maksimum hingga 9 knot. Kapal bantuan Inka Mina di Tegal memiliki dua ukuran panjang yang berbeda berdasarkan data ukuran kapal yang diperoleh dari Kementrian Kelautan Perikanan. Kedua Kapal Inka Mina di Tegal memiliki 
daya penggerak sebesar $170 \mathrm{HP}$. Kapal pertama yang berukuran panjang (LOA) 16,67 m, lebar 5,05 m, dan dalam 2,18 m memiliki nilai ton displacement sebesar 104,61 sehingga kecepatan maksimum yang dapat ditempuh hingga 9,34 knot dengan nilai EHP sebesar 39,13 HP.

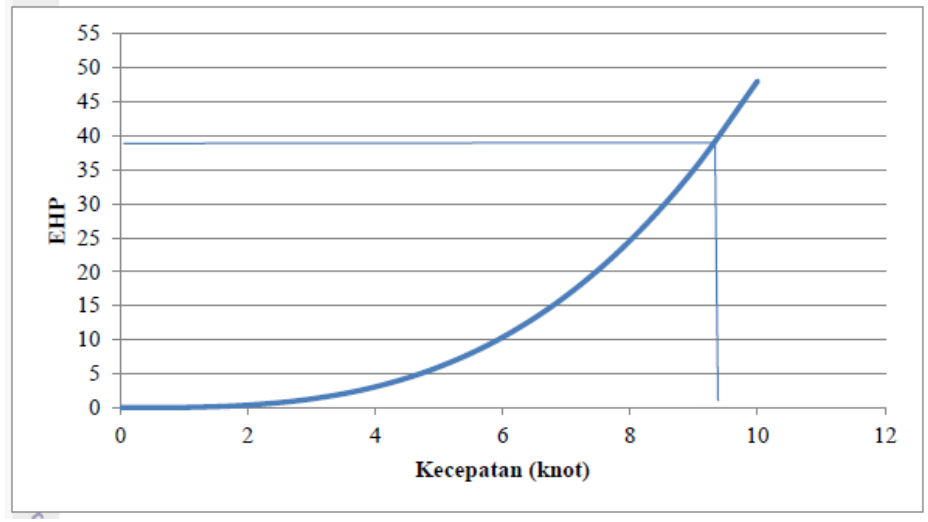

Gambar 6 Kurva kecepatan maksimum Kapal Inka Mina di Tegal (a)

Kapal Inka Mina kedua di Tegal yang memiliki ukuran panjang (LOA) 17,89 m, lebar 5,30 m, dan dalam 2,05 m menghasilkan kecepatan maksimum hingga 9,22 knot dengan daya penggerak hingga 39,13 HP.

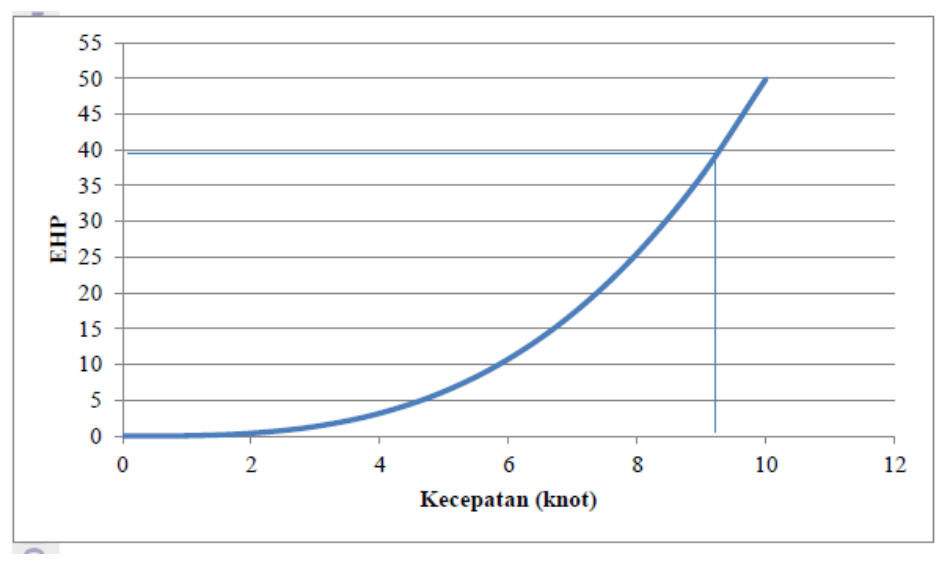

Gambar 7 Kurva kecepatan maksimum Kapal Inka Mina di Tegal (b)

\section{Tingkat Pemanfaatan Pengoperasian Kapal Inka Mina di Indonesia}

Pengoperasian Kapal Inka Mina di beberapa daerah memberikan keuntungan bagi penerimanya dalam bentuk kenaikkan pendapatan masing-masing nelayan mencapai Rp3-4 juta/nelayan/bulan [KKP.A] 2014.

\section{Upaya Pengoperasian Kapal Inka Mina}

Pengoperasian Kapal Inka Mina juga tidak semuanya memperoleh keuntungan seperti yang lain. Seperti halnya KUB di Cilacap dan Tegal melakukan beberapa usaha sebelum dapat mengoperasikan Kapal Inka Mina tersebut, diantaranya:

\section{Perubahan atau Penggantian Konstruksi}

Terdapat beberapa bagian kapal yang diganti dalam pengoperasian Kapal Inka Mina ini, diantaranya:

\section{- Dek Kapal}

Sejak awal pemberian kapal bantuan ini dek kapal yang ada tidak memadai. Dek kapal terlalu rapuh sehingga pemilik kapal pada akhirnya memperbaiki dek kapal dengan cara melaminasi ulang dek kapal tersebut. 


\section{Sheer}

Tinggi sheer pada kapal tidak sesuai sehingga sangat mengganggu keamanan ABK saat melakukan kegiatan di kapal. Kapal yang digunakan oleh nelayan di Cilacap ini melakukan kegiatan operasi penangkapan di daerah ZEE yang merupakan laut lepas dengan gelombang yang tinggi dan sering tidak menentu sehingga nelayan di Cilacap melakukan modifikasi terhadap tinggi sheer yang ada agar keamanan ABK tetap terjaga saat melakukan kegiatan di area dek.

\section{Palka}

Dinding palka yang tipis menjadi kekhawatiran bagi nelayan dalam menyimpan hasil tangkapannya. Tutup palka yang ada dilaminasi ulang agar lebih tebal dan kuat agar suhu udara di dalam palka tetap terjaga dan tidak terpengaruh oleh suhu udara luar (insulasi).

\section{Sistem Pendingin}

Sejak awal sistem pendingin yang ada memiliki sistem terpusat, yaitu satu saluran pendingin untuk semua palka yang selanjutnya diubah menjadi masing-masing palka memiliki sistem pendingin tersendiri.

\section{- Ruang Dek Atas}

Pada beberapa Kapal Inka Mina di Cilacap rumah dek bagian atas ada yang dihilangkan karena dianggap tidak memiliki fungsi yang membantu dalam pengoperasian kapal.

\section{- Ruang Alat Tangkap}

Rumah alat tangkap ini dibuat agar memudahkan penyimpanan alat tangkap di kapal. Lokasi rumah alat tangkap ini ada dibagian haluan kapal.

\section{Bilge keel}

Penambahan panjang bilgee keel atau nelayan biasa menyebutnya sayap kapal, dilakukan agar kapal tetap stabil dan tidak mudah oleng saat menerjang ombak.

Tabel 4 Daftar pemanfaatan Kapal Inka Mina di beberapa daerah di Indonesia

\begin{tabular}{|c|c|c|c|c|c|c|}
\hline \multirow{2}{*}{$\begin{array}{c}\text { No. } \\
1\end{array}$} & \multirow{2}{*}{$\begin{array}{c}\text { Nama Kapal } \\
\text { Inka Mina } 16\end{array}$} & Kab./Kota & Provinsi & \multicolumn{2}{|c|}{$\begin{array}{c}\text { Total } \\
\text { Pendapatan } \\
\text { (milyar) } \\
\text { per tahun }\end{array}$} & \multirow{2}{*}{$\begin{array}{r}\text { Tahun } \\
2010\end{array}$} \\
\hline & & Kab. Luwu & Sulawesi Selatan & $\mathrm{Rp}$ & 2,4 & \\
\hline 2 & Inka Mina 17 & Kab. Luwu & Sulawesi Selatan & $\mathrm{Rp}$ & 1,4 & 2010 \\
\hline 3 & Inka Mina 232 & Kab. Luwu & Sulawesi Selatan & $\mathrm{Rp}$ & 1,2 & 2011 \\
\hline 4 & Inka Mina 03 & Kab. Indragiri Hilir & Riau & $\mathrm{Rp}$ & 1,1 & 2010 \\
\hline 5 & Inka Mina 244 & Kab. Konawe & Sulawesi Tenggara & $\mathrm{Rp}$ & 1,6 & 2010 \\
\hline 6 & Inka Mina 246 & Kota Kendari & Sulawesi Tenggara & $\mathrm{Rp}$ & 4,9 & 2011 \\
\hline 7 & Inka Mina 247 & Kota Kendari & Sulawesi Tenggara & $\mathrm{Rp}$ & 5,4 & 2011 \\
\hline 8 & Inka Mina 41 & Kota Gorontalo & Gorontalo & $\mathrm{Rp}$ & 0.6 & 2010 \\
\hline 9 & Inka Mina 213 & Kab. Gorontalo & Gorontalo & $\mathrm{Rp}$ & 1,5 & 2011 \\
\hline 10 & Inka Mina 215 & Kota Gorontalo & Gorontalo & $\mathrm{Rp}$ & 0.9 & 2011 \\
\hline 11 & Inka Mina 33 & Kota Pekalongan & Jawa Tengah & $\mathrm{Rp}$ & 1 & 2011 \\
\hline 12 & Inka Mina 139 & Kota Pekalongan & Jawa Tengah & $\mathrm{Rp}$ & 1,4 & 2011 \\
\hline 13 & Inka Mina 38 & Kab. Indramayu & Jawa Barat & $\mathrm{Rp}$ & 1 & 2010 \\
\hline 14 & Inka Mina 01 & Kab. Aceh Barat Daya & Aceh & $\mathrm{Rp}$ & 1,6 & 2010 \\
\hline 15 & Inka Mina 50 & Kab. Bireun & Aceh & $\mathrm{Rp}$ & 0.7 & 2011 \\
\hline 16 & Inka Mina 52 & Kab. Aceh Singkil & Aceh & $\mathrm{Rp}$ & 0.7 & 2011 \\
\hline
\end{tabular}




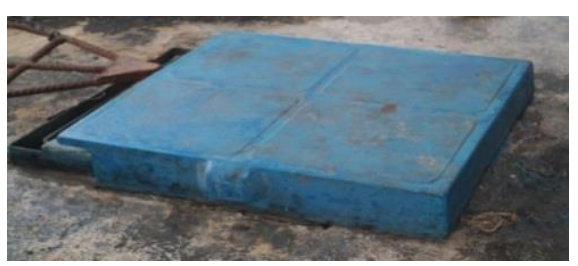

(a)

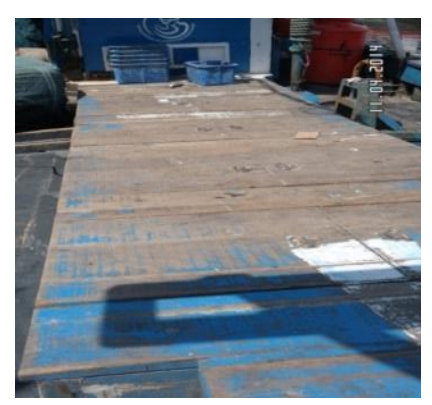

(b)

Gambar 8 Palka ikan di Kapal Inka Mina (a) Cilacap dan (b) Tegal setelah mengalami perbaikan

\section{Alat tangkap}

Alat tangkap yang diberikan kepada nelayan di Cilacap berupa longline dengan ukuran panjang tali utama 3.000 meter dan jumlah mata pancing sebanyak 600 buah. Jumlah pelampung yang diberikan untuk alat tangkap ini hanya 4 buah saja dan itu masih sangat tergolong sedikit atau kurang memadai untuk ukuran tali utama sepanjang 3.000 meter.

Nelayan penerima kapal bantuan Inka Mina di Cilacap mengubah alat tangkap yang telah didapatkan menjadi alat tangkap sesuai yang umumnya mereka gunakan. Alat tangkap yang diperoleh berupa alat tangkap longline diganti menjadi gillnet. Alasan utama yang menyebabkan perubahan alat tangkap ini diantaranya adalah modal yang dibutuhkan dalam pengoperasian longline lebih besar dibandingkan dengan modal pengoperasian gillnet, waktu pengoperasian yang relatif lebih lama, dan jumlah ABK yang lebih banyak, dan kosntruksi kapal yang kurang sesuai untuk melakukan operasional longline.

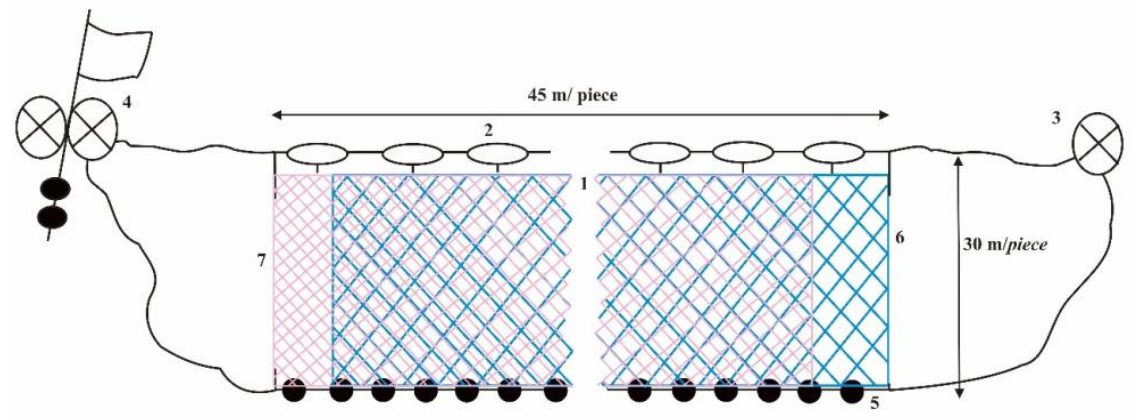

Keterangan :
1. Badan jaring
3. Pelampung tanda
5. Pemberat
7. Jaring 2
2. Pelampung
4. Pelampung bendera
6. Jaring 1

Gambar 91 Tipe Alat tangkap gillnet dua lapis di Cilacap

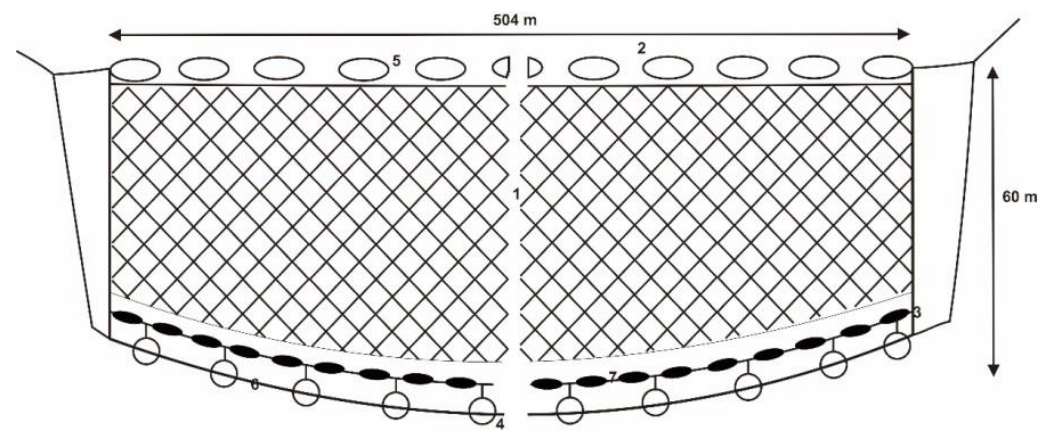

Gambar 10 Tipe Alat Tangkap purse seine di Tegal 

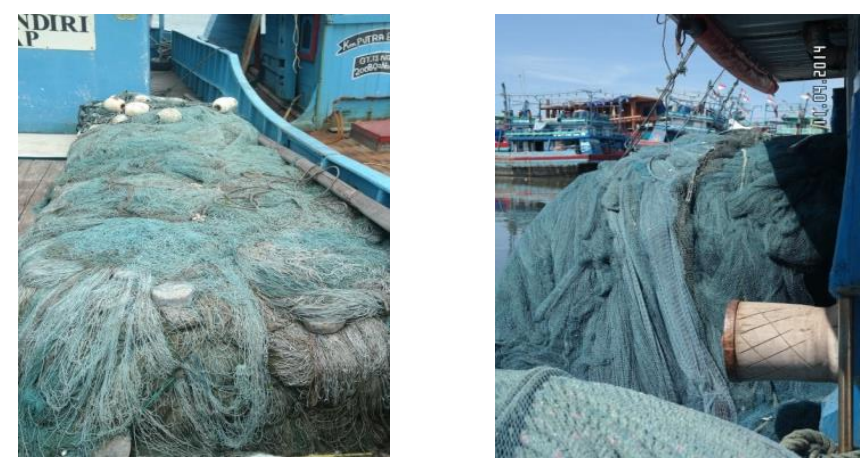

Gambar 11 Alat tangkap purse seine di Tegal

Menurut Keputusan Menteri Kelautan dan Perikanan Republik Indonesia Nomor Kep.06/Men/2010 tentang Alat Penangkapan Ikan Di Wilayah Pengelolaan Perikanan Negara Republik Indonesia [KKP.B] 2014, alat tangkap gillnet dikategorikan dalam kelompok jenis alat penangkapan ikan jaring insang (gillnets and entangling nets) yang merupakan kelompok jaring yang berbentuk empat persegi panjang dilengkapi dengan pelampung, pemberat, tali ris atas dan tali ris bawah atau tanpa tali ris bawah untuk menghadang ikan sehingga ikan tertangkap dengan cara terjerat dan/atau terpuntal dioperasikan di permukaan, pertengahan dan dasar secara menetap, hanyut dan melingkar dengan tujaun menangkap ikan pelagis dan demersal. Gillnet yang digunakan oleh nelayan di Cilacap merupakan gillnet dua lapis dengan ukuran panjang rata-rata 32 depa untuk 1 piece jaring. Gillnet yang digunakan mencapai 40-50 piece sehingga panjang total dari jaring gillnet mencapai 1.920 meter dengan tinggi jaring sebesar 20 depa atau 30 meter. Ukuran mesh size dari gillnet yang digunakan berkisar antara 5-5,5 inchi. Alat tangkap ini dioperasikan di siang hari dengan hasil tangkapan utama berupa cumi-cumi, cakalang, tuna, dan lemadang. Pengoperasian gillnet di Cilacap dilakukan dengan tangan oleh para nelayan.

Nelayan di Tegal memperoleh alat tangkap berupa purse seine dengan ukuran tali kolor 700 meter, float rope sepanjang 504 meter, dan dalam jaring 60 meter. Ukuran mesh size yang digunakan oleh purse seine ini adalah 1 inchi. Menurut Keputusan Menteri Kelautan dan Perikanan Republik Indonesia Nomor Kep.06/Men/2010 tentang Alat Penangkapan Ikan Di Wilayah Pengelolaan Perikanan Negara Republik Indonesia [KKP.B] 2014, alat tangkap purse seine termasuk dalam kelompok jenis alat penangkapan ikan jaring lingkar (surrounding nets) merupakan kelompok alat penangkapan ikan berupa jaring berbentuk empat persegi panjang yang terdiri dari sayap, badan, dilengkapi pelampung, pemberat, tali ris atas, tali ris bawah dengan atau tanpa tali kerut/pengerut dan salah satu bagiannya berfungsi sebagai kantong yang pengoperasiannya melingkari gerombolan ikan pelagis.

\section{Modal}

Modal ini biasanya digunakan untuk keperluan perbekalan ABK. Menurut Nurani dan Wisudo (2007), perbekalan dalam operasi penangkapan meliputi BBM (solar), oli, umpan, perbekalan makanan, air tawar, gas, minyak tanah, dan keperluan perbekalan lainnya. Total modal yang dibutuhkan untuk perbekalan bagi Kapal Longline di Cilacap bisa mencapai Rp61 juta untuk pengoperasian selama 2-3 bulan. Sedangkan modal yang dibutuhkan oleh nelayan gillnet dalam satu kali melakukan trip penangkapan di Cilacap adalah rentang Rp18 juta hingga Rp30 juta untuk 20 hari hingga 2 bulan. Modal yang dibutuhkan dalam sekali melakukan pengoperasian biasanya berbeda-beda. Namun terlihat perbedaan yang signifikan antara modal atau biaya operasional yang dibutuhkan nelayan longline dan gillnet di Cilacap. Sehingga pada akhirnya modal juga menjadi salah satu faktor yang dijadikan alasan bagi nelayan di Cilacap mengubah alat tangkap longline menjadi gillnet.

Nelayan di Tegal melakukan operasi penangkapan dengan alat tangkap purse seine. Perbekalan dalam melakukan trip penangkapan pada nelayan purse seine tidak jauh berbeda dengan perbekalan 
operasi penangkapan longline ataupun gillnet. Biasanya perbekalan yang dibutuhkan dalam operasi penangkapan purse seine berupa ransum, oli, BBM (solar), minyak tanah, air tawar, biaya retribusi, dan rumpon jika menggunakan rumpon (Tambunan, 2014 dan Hertika, 2014). Modal yang umumnya digunakan untuk perbekalan selama trip yang dibutuhkan oleh nelayan Tegal mencapai Rp70 juta untuk satu kali trip.

Tabel 5 Analisis biaya operasional Kapal Inka Mina di Cilacap dan Tegal

\begin{tabular}{lcccc}
\hline \multicolumn{1}{c}{ KUB } & Kapal & Biaya Operasional (Rp) & Penerimaan (Rp) & Laba/Rugi \\
\hline Cilacap: & & & & Rugi \\
Mina Lestari & IMM 152 & $18-20$ juta & - & Rugi \\
Mina Usaha Mandiri & IMM 159 & $20-25$ juta & - & Laba \\
Mina Makmur & IMM 149 & $27-30$ juta & 155 juta & Rugi \\
Mina Jaya & IMM 151 & 50 juta & - & Rugi \\
Tegal: & & & - & Rugi \\
Merdeka Nelayan & IMM 385 & 70 juta & - & juta \\
Karya Mina & IMM 150 & & & \\
\hline
\end{tabular}

Tabel 5 merupakan biaya operasional yang diperlukan oleh masing-masing Kapal Inka Mina dalam salah satu operasi penangkapan yang dilakukan. Data tersebut diperoleh berdasarkan hasil wawancara dengan nelayan penerima Kapal Inka Mina. Keenam Kapal Inka Mina yang terdapat di Cilacap dan Tegal memiliki frekuensi pengoperasian yang berbeda-beda satu sama lain. Modal yang dibutuhkan oleh masing-masing kapal juga berbeda, namun dari keenam kapal tersebut analisis operasional dapat terlihat pada Kapal Inka Mina Makmur 149 KUB Mina Makmur di Cilacap. Kapal Inka Mina Makmur 149 melakukan operasi penangkapan sebanyak 2 kali sejak Kapal Inka Mina diterima. Modal yang dibutuhkan dalam kegiatan pengoperasian Kapal Inka Mina Makmur 149 ini sebesar Rp27 hingga Rp30 juta, namun Kapal Inka Mina Makmur 149 berhasil memperoleh keuntungan dari kedua operasi penangkapan. Pada trip pertama berhasil memperoleh keuntungan sebesar Rp105 juta dan keuntungan yag diperoleh pada trip kedua sebesar Rp 39 juta. Keuntungan yang diperoleh ini selanjuutnya digunakan untuk mengganti modal awal perbaikan kapal yang dikeluarkan oleh penyandang dana KUB Mina Makmur. Kapal Inka Mina lain yang tidak memperoleh keuntungan bukan berarti selalu mendapatkan kerugian dalam setiap pengoperasiannya. Namun penerimaan yang diperoleh memang tidak sebanding dengan biaya operasional yang dibutuhkan, sehingga seringkali pemilik KUB menyatakann jumlah penerimaan yang diperoleh digunakan untuk kesejahteraan ABK kapal.

Ketersediaan modal bagi nelayan Kapal Inka Mina merupakan tanggungjawab dari penyandang dana masing-masing KUB. Penyandang dana jugalah yang dapat menentukan berangkat atau tidaknya Kapal Inka Mina, karena bila modal yang dibutuhkan belum terpenuhi maka kapal tidak dapat melakukan kegiatan operasi penangkapan. Oleh karena itu keberadaan penyandang dana sangatlah penting bagi KUB. Namun tidak semua KUB di Cilacap memiliki penyandang dana yang tetap, berbeda halnya dengan penyandang dana bagi KUB di Tegal yang memiliki penyandang dana tetap yang sama untuk kedua KUB tersebut. Penyandang dana dapat merupakan anggota KUB atau pengusaha lain yang melakukan kerjasama dengan KUB tersebut.

Walaupun DKP telah memberikan arahan bahwa dalam satu KUB harus ada yang bertindak sebagai penyandang dana kenyataannya tidak semua KUB di Cilacap menerapkan arahan tersebut. Karena tidak semua pengusaha juga bersedia menjadi penyandang tetap bagi sebuah KUB. Beberapa KUB di Cilacap mencari pengusaha yang mau menjadi pemodal bagi KUB merek setiap akan melakukan trip penangkapan. Hal tersebut juga yang menjadikan modal sebagai salah satu kelemahan dalam kegiatan pengoperasian Kapal Inka Mina di Cilacap. 


\section{KESIMPULAN}

Dimensi Kapal Inka Mina di Tegal dan Cilacap berbeda sesuai dengan kebutuhan opearional penangkapan ikan. Nilai rasio dimensi utama kapal penangkapan ikan, Kapal Inka Mina di Tegal maupun Cilacap masih berada pada rentang kapal penangkapan ikan di Indonesia. Kecepatan kapal sudah memadai untuk kebutuhan operasional. Kapal Inka Mina yang diberikan kepada nelayan di PPP Tegalsari dan PPS Cilacap sudah dapat dimanfaatkan oleh nelayan walau harus diakukan beberapa perubahan dalam desain dan konstruksi kapal. Pemanfaatan kapal Inka Mina hingga saat ini belum dapat memberikan keuntungan bagi nelayan.

\section{DAFTAR PUSTAKA}

[DJPT-KKP.A] 2014 Direktorat Jenderal Perikanan Tangkap Kementrian Kelautan dan Perikanan Republik Indonesia. 2014. Kapal Inkamina > 30 GT [internet]. [diunduh 2014 Agust 26];tersedia pada: http://simantap.djpt.kkp.go.id/inka-mina

[DJPT-KKP.B] 2014, Keputusan Direktur Jenderal Perikanan Tangkap Nomor KEP.14/KEP-DJPT/2014 tentang Pedoman Pembangunan Kapal Penangkap Ikan Tahun 2014

Hertika A. 2014. Keragaan Perikanan Purse seine Di PPI Muara Angke Jakarta [skripsi]. Bogor (ID): Institut Pertanian Bogor

[INPRES] 2010, Instruksi Presiden No. 1 tahun 2010 tentang Percepatan Pelaksanaan Prioritas Pembangunan Nasional

Iskandar BH, Pujiati S. 1995. Keragaan Teknis Kapal Ikan Beberapa Ikan di Beberapa Wilayah Indonesia. Bogor (ID): Institut Pertanian Bogor. 11-42.

[KKP.A] 2014 Kementrian Kelautan dan Perikanan Republik Indonesia. 2014. Siaran Pers INKA MINA, Tingkatkan Pendapatan Nelayan (No.001/PDSI/HM.310/I/2014) [internet]. [diunduh 2014 Agust 26];Tersedia pada: http://www.kkp.go.id/index.php/arsip/c/10342/INKA-MINATingkatkan-Pendapatan-Nelayan/?category id=

[KKP.B] 2014, Keputusan Menteri Kelautan Dan Perikanan Republik Indonesia Nomor Kep.06/Men/2010 Tentang Alat Penangkapan Ikan Di Wilayah Pengelolaan Perikanan Negara Republik Indonesia

Mulyanto RB, Wahyono A, Pamungkas RS. 2012. Kapal Perikanan (Pengukuran dan Perhitungan). Jakarta (ID): Balai Besar Pengembagan Penangkapan Ikan.

Nazir M. 1988. Metode Penelitian. Jakarta (ID): Ghalia Indonesia. 63-64 hal.

Nomura M, Yamazaki T. 1977. Fishing Techniques. Tokyo (JP): Japan International Cooperation Agency.

Nurani TW, Wisudo SH. 2007. Bisnis Perikanan Tuna Longline. Bogor: Departemen Pemanfaatan Sumberdaya Perikanan, FPIK, IPB.

[PERPRES] 2011, Peraturan Presiden (Perpres) No. 10 tahun 2011 tentang Badan Koordinasi Nasional Penyuluhan Pertanian, Perikanan, Dan Kehutanan.

Tambunan KJH. 2014. Kelayakan Usaha Penangkapan Ikan Dengan Purse seine 56 GT Di Kota Sibolga Sumatera Utara [skripsi]. Bogor (ID): Institut Pertanian Bogor. 